\title{
(i) EOMUN
}

\section{Oficina para elaboração de currículos para vagas de empregos disponibilizadas na cidade de Santa Maria}

\author{
Deivis Costa Pereira ${ }^{1}$, Giovani R. Librelotto ${ }^{1}$, Mariano Dorneles de Freitas ${ }^{1}$, Talles \\ Siqueira Ceolin ${ }^{1}$
}

${ }^{\text {IC }}$ urso de Ciência da Computacão - Universidade Federal de Santa Maria (UFSM) Santa Maria, RS - Brasil

\{dcpereira, librelotto, mdfreitas, tsceolin\}@inf.ufsm.br

\begin{abstract}
This article presents an activity performed during the event entitled "Empregar RS", as well as an analysis of its respective results. This project consists of two workshops, one for each instance of this event. The first was a presentation about creating your own professional resumé, and in the second it was organized by a team to create a resumé for the event participants. The main objective was to provide more knowledge and opportunities to those who are seeking jobs but also present a lack of understanding of this subject.
\end{abstract}

Resumo. Este artigo apresenta um detalhamento de uma atividade realizada durante o evento Empregar $R S$ e uma análise de seus respectivos resultados. $O$ projeto consiste em uma oficina realizada em cada edição do evento, na primeira desenvolveu-se uma apresentação sobre elaboração de currículos profissionais e na segunda organizou-se uma equipe para elaborar currículos para os participantes interessados do evento. O objetivo foi proporcionar mais conhecimento e oportunidades para aqueles que buscavam vagas de emprego mas possuíam uma carência no assunto de currículos pessoais.

\section{Introdução}

A busca pelo emprego formal abrange diversos desafios para a população; entre eles está presente a apresentação de um currículo pessoal para seus cargos almejados. Portanto, a partir de uma parceria entre o grupo PET (Programa de Educação Tutorial) da Universidade Federal de Santa Maria e a FGTAS/Sine (Fundação Gaúcha do Trabalho e Ação Social) surgiu a oportunidade de elaborar uma oficina de ensino sobre elaboração de currículos pessoais e posteriormente, outra oficina com intuito de prestar o serviço de criação de currículos para participantes do evento anual Empregar RS, organizado pela FGTAS/Sine.

A primeira edição do evento que contou com esta parceria ocorreu em junho de 2018, enquanto que a segunda ocorreu em outubro de 2019. Considerado este ser o maior evento de empregabilidade do Estado, ele possui um histórico de reunir centenas de cidadãos em busca de vagas de emprego [Martins 2019]. Além disso, ele proporciona para os participantes oportunidades de entrevistas a partir de parcerias com diversas empresas. O evento também conta com atividades de orientação sobre o mundo do trabalho.

Este projeto teve como motivação a grande carência da capacitação para elaboração de currículos profissionais, visto que frequentemente é um assunto não estudado em nosso sistema de ensino e também é uma queixa comum entre os 
empregadores a qualidade dos currículos recebidos. Portanto, o objetivo desta parceria foi de proporcionar um auxílio técnico para uma parte da população que busca oportunidades no mercado de trabalho, mas que não possuem conhecimentos sobre esta importante etapa de obtenção de empregos.

Este trabalho está organizado na seguinte estrutura: a Seção 2 mostra algumas análises sobre o mercado de trabalho da região e a criação de currículos. A Seção 3 apresenta a metodologia desenvolvida para as duas instâncias deste projeto, detalhando todas as etapas preparatórias e de execução da atividade. Finalmente, a Seção 4 revela os resultados obtidos em números e a Seção 5 descreve a conclusão do artigo.

\section{Revisão Bibliográfica}

Durante a realização deste projeto, inicialmente estudou-se como estava a situação do mercado de trabalho da cidade. A partir disso, definiu-se o melhor formato para a estruturação de um currículo, de acordo com as vagas disponibilizadas. De forma a complementar, foram analisadas as opiniões e experiências de membros do FGTAS/Sine sobre estes assuntos.

\subsection{Mercado de Trabalho em Santa Maria}

Tendo em vista que um documento de currículo pessoal deve seguir orientações de acordo com o setor do cargo almejado, é fundamental analisar as principais oportunidades de emprego da cidade foco deste projeto.

Entre os anos de 2005 e 2014, a microrregião de Santa Maria obteve um dos maiores crescimentos médio anual de postos formais de trabalho na área de serviços do sul do Brasil [Wenningkamp et al. 2017], portanto, estabelecendo um setor importante a ser considerado durante a elaboração dos currículos. Estes dados foram ratificados por representantes do FGTAS/Sine, durante a edição desta atividade no ano de 2019, pois surgiu a informação de uma quantidade significativa de vagas em uma nova unidade da rede de lojas da empresa Havan. A nova unidade da rede de lojas estava em processo de seleção de candidatos para cargos de auxiliar de vendas, operador comercial e de caixa, vendedor, conferente de estoque, auxiliar de visual merchandising, fiscal de loja e zeladoria, corroborando a tendência de crescimento do setor de comércio na região [Wenningkamp et al. 2017]. Segundo a empresa, os currículos entregues deveriam ser impressos e conter obrigatoriamente os campos: nome completo, endereço, telefone e e-mail [Redação Diário 2019].

A partir do gráfico apresentado na Figura 1 é possível observar que, em geral, há um histórico levemente positivo do saldo de emprego formal (diferença entre admissões e desligamentos) na cidade de Santa Maria ao decorrer dos últimos 14 anos. Em comparação as crises destacadas dos anos de 2008 e 2015, é marcante o impacto da pandemia de 2020 na economia formal da cidade, onde ocorreu a maior queda no número de admissões dos anos listados no gráfico, e por consequência, causando uma grande queda no saldo [Naressi Cardoso 2020]. 




Figura 1. Gráfico do saldo de emprego formal de Santa Maria/RS [Naressi Cardoso 2020]

\subsection{Currículo}

Conhecido por "curriculum vitae" ou "CV", o termo de origem latina significa trajetória de vida. Portanto, trata-se de um documento de caráter histórico e pessoal que busca mostrar de forma concisa o trajeto acadêmico e profissional de uma pessoa. Este documento serve como a primeira apresentação de alguém que almeja um determinado cargo, reúne todas as informações essenciais para serem avaliadas por profissionais buscando contratações e deve ser atualizado constantemente [Germano 2019].

Dentre as informações essenciais de um currículo, destacam-se dados pessoais como nome completo, e-mail e telefone. Outros dados como endereço completo, redes sociais, estado civil e idade costumam ser considerados opcionais ou até mesmo irrelevantes [Guia da Carreira 2015]. Além disso, é de grande importância a apresentação do histórico de formação acadêmica, qualificações e um histórico profissional [da Matta 2013]. Em casos de conhecimento de idiomas estrangeiros ou certificações de cursos, recomenda-se inserir estas seções no documento [Guia da Carreira 2015]. Visto que existe uma grande abrangência de estruturas de currículos e também cada empresa pode ter suas próprias preferências e recomendações, é altamente incentivado adaptar o conteúdo e estrutura do documento de acordo com o cargo almejado. 


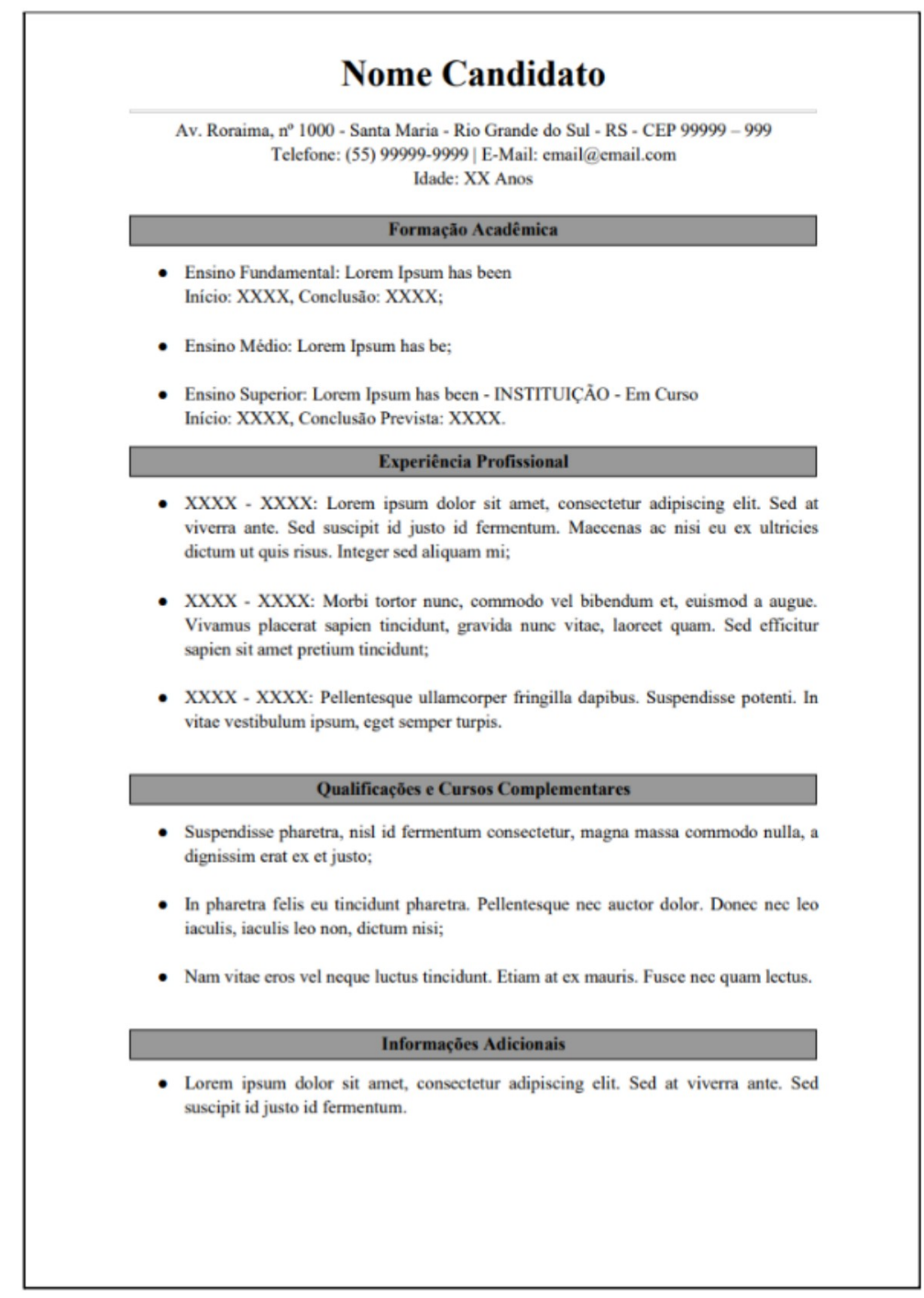

Figura 2. Modelo de documento de currículo

Existem informações comumente consideradas desnecessárias ao documento, o tornando demasiadamente extenso [Relevo 2019]. Algumas destas informações são listagens de hobbies e interesses pessoais, estas embora sejam características marcantes de uma pessoa, não são relevantes para um documento profissional que visa seriedade e concisão. Elogios, juízos de valor, habilidades técnicas obsoletas e foto pessoal muitas vezes são inseridas para se caracterizar melhor, porém acabam sendo consideradas desnecessárias pela empresa contratante.

Como base para a estruturação do currículo usado na edição do evento do ano de 2019, as vagas ofertadas pela loja Havan [Redação Diário 2019] foram consideradas como principal objetivo.

\section{Metodologia}

A oficina de elaboração de currículos, dentro do "Empregar RS", quanto ao seu método, possui características intrínsecas em abordagens de atendimento ao público variado. Em 
suas duas edições, a oficina contou com abordagens parcialmente distintas. A primeira edição possuiu um caráter mais expositivo, enquanto a segunda edição teve um caráter mais prático. Contudo, ambas edições seguiram três etapas comuns, preparação, realização do evento e pós-evento, estas etapas serão descritas e aprofundadas nas próximas subseções.

\subsection{Preparação}

A etapa de preparação consiste nas ações realizadas antes da execução da oficina, sendo composta pelas seguintes atividades:

1. contato com a agência do FGTAS/Sine, agência de Santa Maria - RS, para verificar a necessidade desta oficina;

2. com tal confirmação, estruturaram-se reuniões com os responsáveis da agência e sobre o evento Empregar RS, visando alinhar as atividades a serem oferecidas e realizadas no dia do evento;

3. treinamento de capacitação com os monitores da oficina, com o foco na questão de comunicação, atendimento ao público e boas práticas para elaboração de um currículo.

$\mathrm{O}$ fato de terem sido realizadas duas edições em anos consecutivos auxiliou a etapa 1 na segunda edição da parceria. No primeiro ano, o PET foi consultado sobre alguma capacitação que poderia levar ao Empregar RS. Com a experiência da primeira edição, entendeu-se melhor a necessidade dos postulantes às vagas de emprego, permitindo uma elaboração mais adequada da capacitação proposta.

\subsection{Primeira Edição - 2018}

Na primeira edição do evento adotou-se o método de apresentação oral, abordando o conceito de um currículo, estrutura e diagramação, boas práticas e erros comuns. $\mathrm{O}$ objetivo era realizar uma espécie de seminário com os candidatos a emprego, de forma a apresentar os aspectos essenciais na elaboração do seu próprio currículo, bem como regras de formatação.

Esses seminários possuíam o tempo estipulado de 10 minutos. Era realizado em uma sala, com lotação máxima de 40 pessoas por sessão. Ao final de cada sessão, destinavam-se cerca de 5 minutos para sanar dúvidas dos presentes.

Durante o turno desta oficina, na edição de 2018, foram realizados 6 seminários, cada um deles com um conjunto distinto de participantes. Cada seminário foi realizado com um intervalo de 10 minutos entre o final de um e o início de outro, para poder auxiliar os participantes sobre suas dúvidas ao final da apresentação.

Para a elaboração da apresentação instrutiva desta edição, diversos guias e sites especializados em dicas e montagem de leiautes de currículos foram consultados [Relevo 2019] [da Matta 2013]. Certas etapas, como informações essenciais, erros comuns e boas práticas em um currículo foram importantes no aprendizado de como estruturar um currículo. Embora não exista apenas uma forma definitiva de elaborar um currículo, o objetivo desta edição foi de apresentar um formato simplificado, porém objetivo, do histórico escolar e profissional de cada candidato. 
A principal dificuldade encontrada nesta edição foi porque os seminários precisaram ser realizados em paralelo ao evento principal. Desta forma, os participantes tinham que optar entre participar de divulgação de vagas de trabalho e o seminário, que ocorreram em simultâneo.

\subsection{Segunda Edição - 2019}

A segunda edição adotou um método prático para a oficina, em comparação com a edição do ano anterior. Em vez de realizar seminários apresentando como elaborar currículos, em 2019 os monitores da oficina realizaram atendimentos pessoais para a diagramação e impressão de currículos para os participantes do evento interessados.

O desafio desta nova abordagem se dá principalmente pelo fato de que, assim, os atendimentos individuais acabam trazendo as particularidades de cada candidato. $\mathrm{O}$ método definido pelos participantes foi de, em primeiro lugar, ouvir as experiências dos candidatos para, em seguida, sintetizar as informações relevantes para as vagas buscadas pelo candidato.

Adotou-se um modelo comum de currículo, o qual foi ajustado para cada candidato. Este processo encontrou diversas dificuldades, pois alguns candidatos possuíam somente versões manuscritas de seu próprio currículo, enquanto outros apenas tinham alguns certificados junto à sua carteira de trabalho para comprovar a experiência. Como descrito na Figura 2, o trabalho dos monitores era de extrair as informações da documentação entregue e popular o conteúdo do currículo. A Figura 3 apresenta como cada atendimento individual estava sendo realizado.

Após a edição da versão particular de cada currículo, buscou-se realizar a impressão de duas cópias da versão produzida: uma para o candidato manter em posse para futuras vagas e outra para ser entregue durante o evento para a vaga pretendida. Além disso, uma versão editável, em formato ODT (Open Document Format), foi enviada aos candidatos que possuíam e-mail.

Nesta abordagem percebeu-se um aproveitamento melhor dos conhecimentos compartilhados pelo grupo PET, no que tange a construção de currículos, pois os candidatos participavam de sua construção, entendendo os aspectos fundamentais que devem fazer parte do $\mathrm{CV}$, bem como das informações que não são relevantes, dependendo da vaga procurada. 


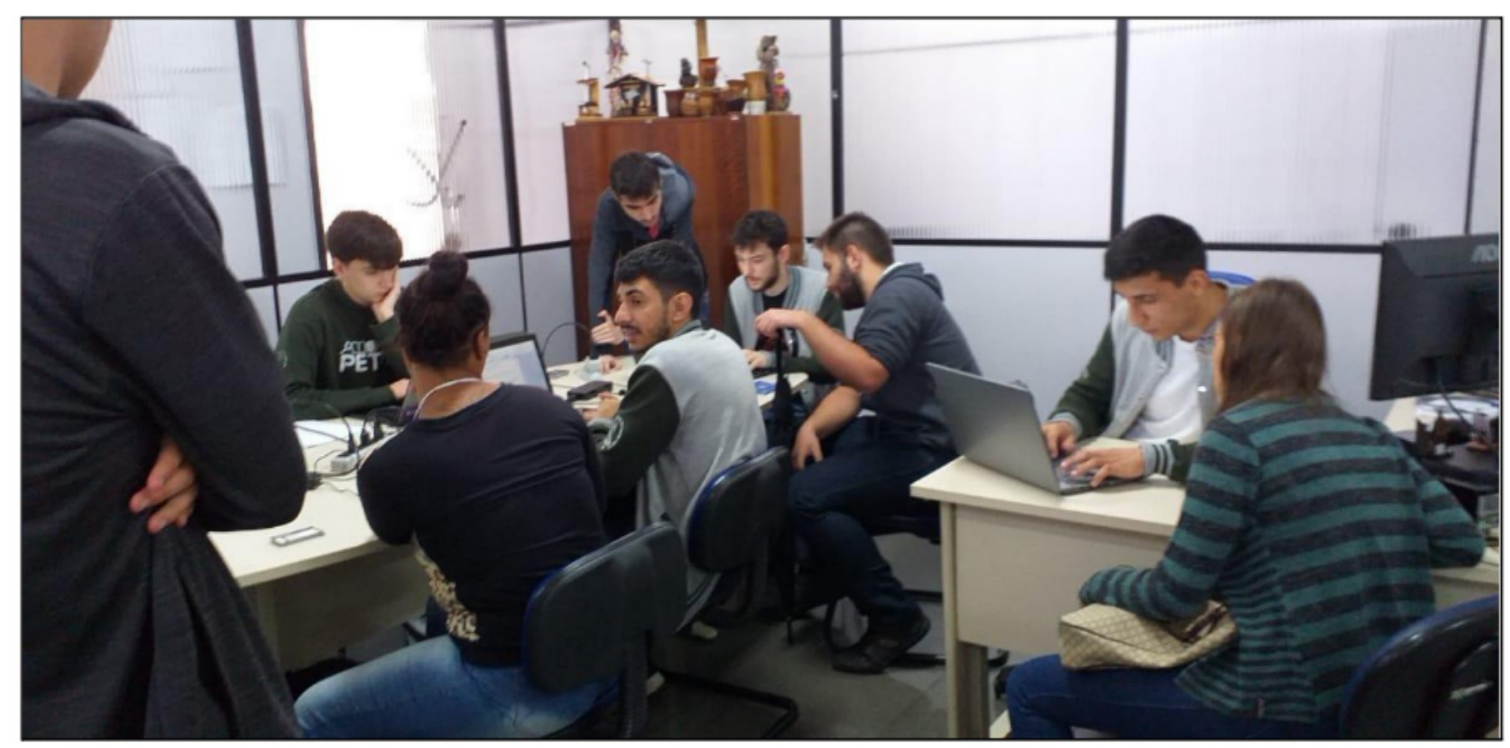

Figura 3. Momento de funcionamento da oficina, onde os membros do PET atendiam aos participantes do evento.

Em contrapartida, esta abordagem faz com que o número de atendimentos seja limitado, por realizar um atendimento individual com cada candidato. Enquanto na edição de 2018 até 40 pessoas poderiam ser atendidas em 30 minutos (no formato seminário), em 2019 dependia do número de monitores disponíveis. Como eram 5 monitores atuando em paralelo e cada um conseguia elaborar 2 currículos a cada 30 minutos, o número de pessoas atendidas caiu de 40 para 10 , no mesmo período.

\subsection{Pós-Evento}

Esta etapa foi destinada à coleta de opiniões e avaliações sobre a oficina, junto ao FGTAS/Sine, buscando sugestões de melhoria, novas abordagens que possam ser empregadas e resultados obtidos. Também compõe a etapa do pós-evento a elaboração de relatórios sobre o evento, voltados ao controle interno do grupo organizador. A Figura 4 apresenta o encerramento da segunda edição do evento, após a deliberação entre os monitores e a comissão organizadora do evento. 


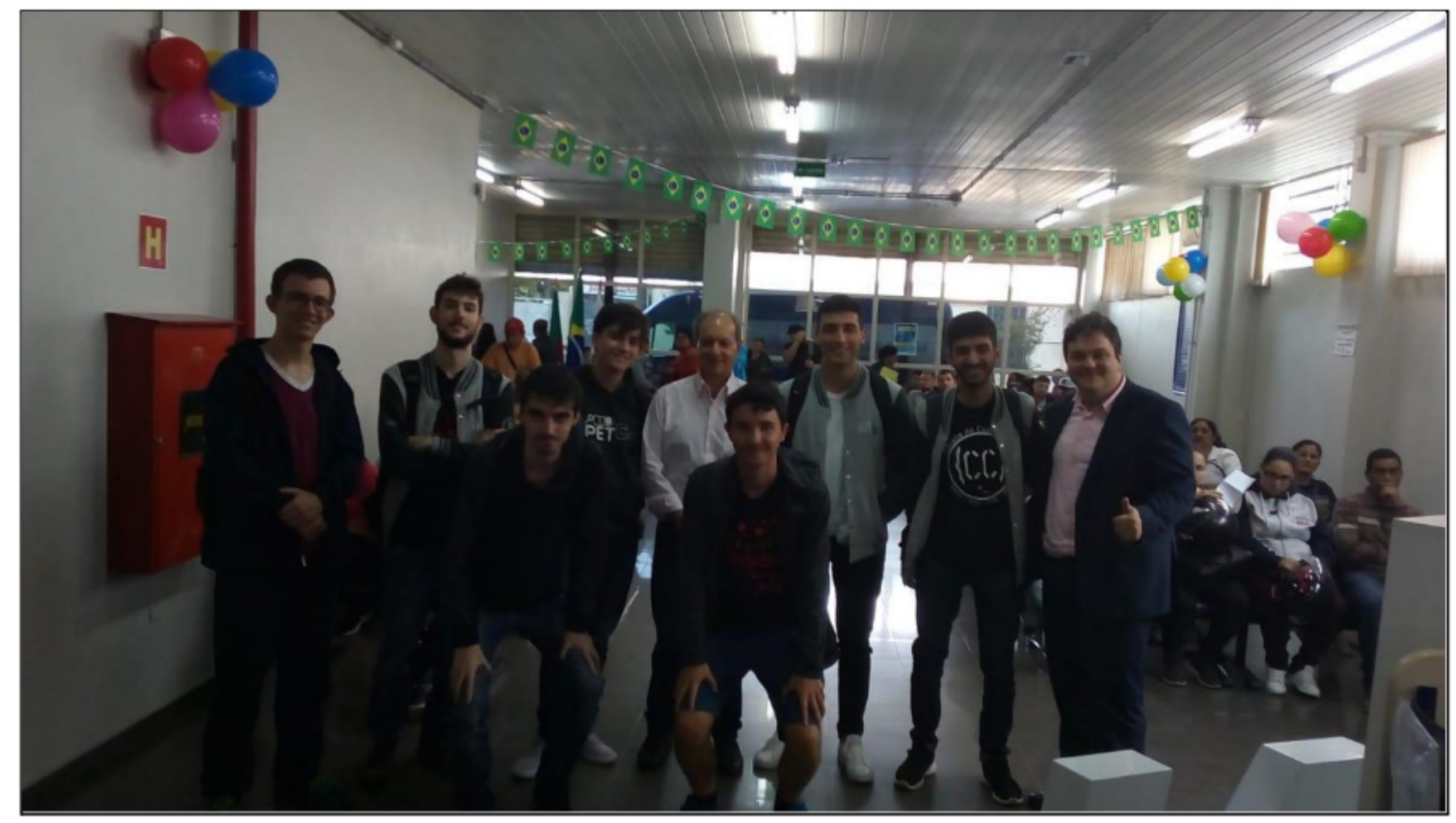

Figura 4. Membros do PET junto a parte da comissão organizadora do evento.

\section{Resultados Obtidos}

Foram realizadas duas edições do evento, uma no modelo de palestras (em 2018) e outra como confecção de currículos (em 2019). A mudança de abordagem entre as duas edições deu-se pela experiência obtida na primeira, notou-se a demanda de currículos, uma vez que alguns candidatos possuíam apenas currículos escritos à mão ou incompletos, desta forma, discutiu-se internamente a possibilidade de mudança e a oficina foi adaptada.

$\mathrm{Na}$ primeira edição, os candidatos demonstraram interesse nos métodos apresentados, inclusive participando com perguntas aos responsáveis pela oficina. Pelas estimativas do FGTAS/Sine, durante o turno de realização da oficina, 77 (setenta e sete) pessoas participaram dos seminários preparados. Por mais que a sala possuísse capacidade para até 40 pessoas ao mesmo tempo, os seminários geralmente tinham apenas metade da lotação da sala a cada execução. Este foi um dos argumentos que serviram de motivação da decisão de modificar a oficina para a edição do ano seguinte. Outro ponto que também influenciou a relativa baixa participação dos candidatos no evento foi que ele aconteceu no mesmo dia de jogos da Copa do Mundo de futebol, realizada em 2018.

$\mathrm{Na}$ segunda edição foram confeccionados, impressos e entregues 35 (trinta e cinco) currículos aos candidatos às vagas disponíveis durante o turno de realização da oficina. Isso deu uma média de 7 atendimentos por cada monitor. Este número poderia ser ainda maior, pois o evento principal contava com enorme fluxo de pessoas (inclusive maior que no ano anterior); contudo, não haviam monitores disponíveis para o atendimento de mais pessoas, o que servirá de preparação para a próxima edição. 
Desta forma, observou-se uma boa adesão dos participantes do evento à oficina em cada uma das edições do evento. A demanda observada na primeira edição da oficina mostrou-se importante, uma vez que diversos participantes necessitavam da confecção de currículos para poderem concorrer às vagas ofertadas e conseguiram entender isso, através dos seminários ministrados. Entretanto, a abordagem adotada na segunda edição foi mais eficiente, pois os candidatos saiam da oficina com o conhecimento do seminário do ano anterior na prática, pois participavam da elaboração de seu próprio currículo, junto ao monitor do PET.

Ao grupo, a troca de experiências com a comunidade e o retorno do investimento se mostrou essencial para a formação dos integrantes. Assim como esperado de uma atividade extensionista, esta atividade proporcionou uma experiência além da sala de aula e laboratórios, auxiliando na formação cidadã dos membros e proporcionando um impacto social aos participantes da oficina e organizadores do evento.

Para a edição de 2020 do Empregar RS, planejava-se repetir a abordagem de 2019, onde os monitores do PET atuariam pessoalmente, de forma individual, com cada candidato a emprego na elaboração de seu currículo. Entretanto, em função da pandemia da COVID-19, o projeto ficará adiado para 2021, mais uma vez em parceria com o FGTAS de Santa Maria.

\section{Conclusão}

Em um mercado de trabalho cada vez mais concorrido e com vagas cada vez mais especializadas, os cuidados na elaboração de um currículo são de suma importância para aumentar as chances do candidato de ocupar a vaga desejada. De posse dessa premissa, o PET se preocupou em como colaborar com a comunidade de Santa Maria, oferecendo duas capacitações com esta temática dentro do Empregar RS.

A primeira experiência da oficina foi essencial para identificar as demandas do público alvo deste treinamento. O modelo de palestras sobre a confecção atingiu o objetivo inicialmente proposto, que era compartilhar o conhecimento sobre o tema. Entretanto, neste formato não foi possível analisar se os participantes dos seminários realmente conseguiram absorver os ensinamentos, pois não havia uma avaliação sobre o conteúdo abordado.

Por sua vez, em seu segundo formato, a oficina baseada em atendimentos particulares provou-se necessária e eficaz, pois a demanda foi parcialmente atendida; eram necessários mais monitores para atender todos os interessados. Contudo, é possível observar as desvantagens nesse modelo de oficina, uma vez que o conhecimento sobre montagem do currículo não necessariamente é passado adiante, pois em boa parte dos atendimentos os candidatos não se preocuparam em aprender como fazer seu currículo: o importante era que o monitor o fizesse.

Para as próximas edições, está em planejamento a realização de uma abordagem híbrida, envolvendo uma palestra e a confecção de currículo ao final do atendimento, de maneira a não só auxiliar aqueles que possuem dificuldades na criação, mas capacitá-los para uma necessidade futura. 
Outro projeto em análise para as próximas edições será de envolver outros grupos PET da Universidade, não somente para aumentar o número de monitores nos atendimentos, mas principalmente para realizar uma análise no modelo de currículos mais apropriado para cada edição, de acordo com as empresas que estarão ofertando as vagas e também ao tipo de vagas que estarão sendo disponibilizadas.

\section{Referências Bibliográficas}

Wenningkamp, K., Ferrera de Lima, J., Predroza Lobão, M. (2017). Evolução e qualificação do emprego formal no sul do Brasil, Anais do VIII Seminário Internacional sobre Desenvolvimento Regional

Redação Diário (2019). Seleção para vagas da Havan em Santa Maria começa na segunda-feira. Disponível em: https://diariosm.com.br/not\%C3\%ADcias/geral/sele\%C3\%A7\%C3\%A3o-para-vagas-da -havan-em-santa-maria-come\%C3\%A7a-na-segunda-feira-1.2159070.

da Matta, V. (2013). Guia do currículo - Como elaborar um currículo perfeito?.

Disponível em: https://www.sbcoaching.com.br/blog/guia-do-curriculo-elaborar-curriculo-perfeito/

Relevo (2019). O que não colocar no currículo: 11 erros que você deve evitar. Disponível em: https://blog.revelo.com.br/o-que-nao-colocar-no-curriculo-11-erros-que-voce-deve-evita r/.

Martins J. (2019). Empregar RS 2019. Disponível em: https://stas.rs.gov.br/empregar-rs

Jornal do Almoço (2019). Sine Santa Maria oferece mais de cem vagas em mutirão de emprego. Disponível em: https://globoplay.globo.com/v/8015530/.

Diário de Santa Maria (2019). O Empregar RS ofertou mais de 100 vagas em Santa Maria. Disponível em: https://www.youtube.com/watch?v=xurLSkcHCj0.

Rizzetti Coradini, J., Taschetto Murini, L. (2009). Recrutamento e seleção de pessoal: com agregar talentos à empresa. Revista Eletrônica Disciplinarum Scientia, 5(1).

Leite, P. (2018). Pormenores no curriculum vitae: O impacto da prática desportiva no processo de recrutamento e seleção. PORG - Dissertações de Mestrado.

Eberhardt, P., Cardoso, B. (2017). Perfil locacional do emprego formal nas microrregiões do Rio Grande do Sul. Revista DRd: Desenvolvimento Regional em debate, 7, p. 144-163.

Leme Souza, R. (2020). Uma breve comentário do mercado de trabalho do Brasil. Revista de Ciencias Empresariales y Sociales, 2, p. 26-41.

Germano, S. (2019). Diferença entre Currículo Vitae e Currículo Lattes. Disponível em http://www.anpg.org.br/12/03/2019/diferenca-entre-curriculo-vitae-e-curriculo-lattes.

Guia da Carreira (2015). O que colocar no currículo. Blog Guia da Carreira. Disponível em: https://www.guiadacarreira.com.br/ 
Naressi Cardoso, M., Léia Becker, K. (2020). Impactos da COVID-19 no mercado de trabalho formal de Santa Maria/RS - Análise dos meses de março e abril de 2021. Análise de conjuntura do Observatório Socioeconômico da Covid-19. Disponível em: https://www.ufsm.br/app/uploads/sites/820/2020/06/Ana\%CC\%81lise-de-Conjuntura-0 6.pdf 